\title{
CONVEXITY ACCORDING TO MEANS
}

\author{
Constantin P. Niculescu
}

Abstract. Given a function $f: I \rightarrow J$ and a pair of means $M$ and $N$, on the intervals $I$ and $J$ respectively, we say that $f$ is $M N$-convex provided that $f(M(x, y)) \leqslant N(f(x), f(y))$ for every $x, y \in I$. In this context, we prove the validity of all basic inequalities in Convex Function Theory, such as Jensen's Inequality and the Hermite-Hadamard Inequality.

Mathematics subject classification (2000): 26A51, 26D07, 26D15, 60A10.

Key words and phrases: convex function, mean, random variable.

\section{REFERENCES}

[1] H. Alzer, On an integral inequality, Math. Rev. Anal. Numer. Th. Approx., 18 (1989), 101-103.

[2] E. ARTIN, The Gamma Function, Holt, Rinehart and Winston, New York, 1964. English translation of German original, Einführung in die Theorie der Gammafunktion, Teubner, 1931.

[3] H. Bohr AND J. MolleruP, Laerebogi i mathematisk Analyse, vol. III, pp. 149-164, Kopenhagen, 1922.

[4] D. Borwein, J. Borwein, G. FeE And R. Girgensohn, Refined convexity and special cases of the Blaschke-Santalo inequality, Math. Inequal. Appl., 4 (2001), 631-638.

[5] J. L. Brenner And B. C. CARLSOn, Homogeneous mean values: weights and asymptotics, J. Math. Anal. Appl., 123 (1987), 265-280.

[6] P. S. Bullen, D. S. Mitrinović And P. M. Vasić, Means and Their Inequalities, D. Reidel Publishing Company, Dordrecht, 1988.

[7] G. T. CARgo, Comparable means and generalized convexity, J. Math. Anal. Appl., 12 (1965), $387-392$.

[8] B. C. CARLSON, Algorithms involving arithmetic and geometric means, Amer. Math. Monthly, 78 (1971), 496-505.

[9] N. ElEZOVIĆ AND J. PEČARIĆ, Differential and integral F-means and applications to digamma function, Math. Inequal. Appl., 3 (2000), 189-196.

[10] G. Hardy, J. E. Littlewood And G. Pólya, Inequalities, Cambridge Mathematical Library, 2nd ed., 1952, Reprinted 1988.

[11] J. LAMPERTI, On the isometries of certain function-spaces, Pacific J. Math., 8 (1958), 459-466.

[12] S. M. Malamud, Some complements to the Jensen and Chebyshev inequality and a problem of W. Walter, Proc. Amer. Math. Soc., 129 (2001), 2671-2678.

[13] J. MatKowski AND J. RÄTZ, Convexity with respect to an arbitrary mean, Int. Ser. Numer. Math., 123 (1997), 231-247.

[14] P. Montel, Sur les functions convexes et les fonctions sousharmoniques, Journal de Math., (9) 7 (1928), 29-60.

[15] M. E. MAYES, Functions which parametrize means, Amer. Math. Monthly, 90 (1983), 677-683.

[16] C. P. NiCULESCU, Convexity according to the geometric mean, Math. Inequal. Appl., 3 (2000), $155-167$.

[17] C. P. NICULESCU, A multiplicative mean value and its applications. In: Inequality Theory and Applications vol. 1, pp. 243-256, Nova Science Publishers (USA), 2001. (Y. J. Cho, S. S. Dragomir and J. Kim, Editors)

[18] A. W. Roberts and D. E. VArberg, Convex functions, Academic Press, New York and London, 1973. 